\title{
Effects of simulated predation on tonic immobility in Anolis carolinensis: The role of eye contact
}

\author{
CHARLES W. HENNIG \\ Tulane University, New Orleans, Louisiana 70118
}

\begin{abstract}
The importance of eyes and fabricated eye-like stimuli in prolonging tonic immobility in the lizard (Anolis carolinensis) was examined in four experiments. The direct gaze of an experimenter was found to prolong the duration of tonic immobility relative to an averted gaze. Detached glass eyes also produced a similar effect, although not as profoundly as the presence of a live experimenter. By varying pupil size, it was shown that the strongest effect was caused by an eye with a large black pupil, but that the absolute size of the eye was not significantly related to the increased durations of immobility.
\end{abstract}

Although known for several centuries, there has been a recent revival of interest in tonic immobility (TI). This response is observed in a wide variety of species when, upon removal of manual restraint, the animal exhibits a prolonged but reversible state of physical immobility. One hypothesis that has received wide attention and considerable empirical support suggests that TI evolved as a predator defense (for a more complete statement and current review, see Gallup, 1974). In support of the predation hypothesis, Sargeant and Eberhardt (1975) found that 29 out of 50 wild ducks which became immobile during predatory encounters with red foxes survived the initial attack. In addition, laboratory studies have shown that response duration can be prolonged by the visual presence of the experimenter in both chickens (Gallup, Cummings, \& Nash, 1972) and anoles (Edson \& Gallup, 1972) or the presence of a stuffed Cooper's hawk (Gallup, 1973; Gallup, Nash, Donegan, \& McClure, 1971).

One feature of a potential predator which seems to be critically important in enhancing the duration of the immobility response appears to be the predator's eyes. Gallup, Nash, and Ellison (1971) have shown that even detached glass eyes, suspended from wooden dowels, substantially prolong immobility durations in chickens. In addition, Gallup (1972) has shown that chickens immobilized in front of a dead conspecific with its eyes sewn open or in front of their own mirror image show significantly longer response durations than subjects immobilized in front of a dead conspecific with its eyes closed. More recently, O'Brien and Dunlap (1975) demonstrated similar effects of artificial eyes on durations of TI in the blue crab.

Portions of this paper were presented at the meeting of the Southeastern Psychological Association in New Orleans in March 1976. This paper is sponsored by William P. Dunlap, who takes full editorial responsibility for its contents. Requests for reprints should be sent to Charles W. Hennig, Department of Psychology, Tulane University, New Orleans, Louisiana 70118.
The present study attempts to replicate and extend some of these earlier findings on the effects of eye contact on TI, but employs the anole as a subject instead of the more commonly used domestic chicken.

\section{EXPERIMENT 1}

The first experiment was designed to replicate the finding of Gallup, Cummings, and Nash (1972) in chickens, that eye contact between the experimenter and the subject prolongs tonic immobility.

\section{Method}

Subjects. Twenty lizards (Anolis carolinensis), of both sexes and ranging in length from 4 to $7 \mathrm{~cm}$ (snout-vent), were collected locally after dark. All subjects were housed in two glass terrariums, measuring $52 \times 27 \times 30 \mathrm{~cm}$, with water continuously available but food not provided. Room temperature was maintained at approximately $25^{\circ} \mathrm{C}$ and the photoperiod in effect throughout the study consisted of $12 \mathrm{~h}$ of artificial light (7:00 a.m.-7:00 p.m.). All of the lizards were housed in the laboratory for 1 day prior to testing.

Apparatus and procedure. The anoles were randomly divided into two groups of 10 subjects each before testing. The experimental procedure consisted of seizing the anole and placing it on its back on a table, with the anole's head oriented toward the experimenter. Gentle pressure was maintained for $20 \mathrm{sec}$, with the experimenter placing one finger at the base of the anole's lower jaw and another at the tip of its tail. At the end of this time, the experimenter slowly withdrew his hands. In the control condition, the experimenter sat down $60 \mathrm{~cm}$ away and observed the subject peripherally with his gaze averted $45 \mathrm{deg}$ to the right. In the experimental group, the experimenter was seated at the same distance but attempted to maintain direct eye contact with the anole. The duration of TI was measured with a stopwatch from the release of the subject until a spontaneous righting response occurred or a maximum of $900 \mathrm{sec}$ elapsed. If immobility did not last a minimum of $10 \mathrm{sec}$ on the first attempt, the induction procedure was immediately repeated until TI occurred. The number of inductions and the duration of TI were recorded for each subject.

\section{Results}

Means and standard deviations for the duration of immobility and the number of inductions needed for 
Table 1

Means and Standard Deviations of Durations of Immobility (in Seconds) and Number of Inductions for Experiments 14

\begin{tabular}{|c|c|c|c|c|c|}
\hline \multirow[b]{2}{*}{ Group } & \multirow[b]{2}{*}{$\mathrm{N}$} & \multicolumn{2}{|c|}{$\begin{array}{c}\text { Durations of } \\
\text { Immobility }\end{array}$} & \multicolumn{2}{|c|}{$\begin{array}{l}\text { Number of } \\
\text { Inductions }\end{array}$} \\
\hline & & Mean & SD & Mean & SD \\
\hline \multicolumn{6}{|c|}{ Experiment 1} \\
\hline Direct gaze & 10 & 622.2 & 238.5 & 1.9 & 1.0 \\
\hline Averted gaze & 10 & 339.1 & 232.1 & 2.8 & 1.6 \\
\hline \multicolumn{6}{|c|}{ Experiment 2} \\
\hline Glass eyes & 15 & 415.7 & 248.3 & 3.8 & 2.0 \\
\hline Bare dowels & 15 & 243.5 & 220.1 & 2.6 & 1.7 \\
\hline \multicolumn{6}{|c|}{ Experiment 3} \\
\hline Total black spot & 6 & 245.2 & 187.2 & 1.3 & .5 \\
\hline 9-mm pupil radius & 6 & 715.2 & 306.4 & 3.2 & 1.2 \\
\hline $7-\mathrm{mm}$ pupil radius & 6 & 505.3 & 348.0 & 1.8 & .8 \\
\hline $5-\mathrm{mm}$ pupil radius & 6 & 431.7 & 274.5 & 1.8 & 1.0 \\
\hline $3-\mathrm{mm}$ pupil radius & 6 & 215.0 & 99.7 & 2.3 & 1.2 \\
\hline $1-\mathrm{mm}$ pupil radius & 6 & 241.0 & 180.0 & 2.0 & .9 \\
\hline Total yellow spot & 6 & 204.2 & 179.7 & 2.0 & .9 \\
\hline \multicolumn{6}{|c|}{ Experiment 4} \\
\hline Large eye & 11 & 543.6 & 300.2 & 1.5 & .5 \\
\hline Medium eye & 11 & 396.3 & 226.3 & 1.6 & 1.0 \\
\hline Small eye & 11 & 461.3 & 332.2 & 2.1 & 1.0 \\
\hline Bare dowel & 11 & 236.7 & 245.7 & 2.6 & 1.6 \\
\hline
\end{tabular}

response elicitation can be seen in Table 1 . The direct gaze of the experimenter produced durations of immobility that were almost twice as long as that of an averted gaze. Since duration scores were positively skewed, a transformation $(\sqrt{\mathrm{X}})$ was performed on the raw scores and an ANOVA showed a significant difference between the groups $[F(1,18)=8.41, p<.01]$. The number of inductions were not statistically different.

\section{EXPERIMENT 2}

The second experiment was designed to replicate and extend earlier findings from Gallup, Nash, and Ellison (1971) with chickens and from O'Brien and Dunlap (1975) with blue crabs-that detached glass eyes can prolong tonic immobility.

\section{Method}

The subjects were 30 anoles, captured and maintained as in the previous experiment. The general materials were the same, except that a pair of yellow glass eyes with black pupils was used. The glass eyes measured approximately $2 \mathrm{~cm}$ in diam (see Gallup et al., 1971 for a photograph) and were mounted on the end of a pair of wooden dowels, set $2.5 \mathrm{~cm}$ apart and inserted through holes in a wooden plank. The ends of the dowels were positioned $13 \mathrm{~cm}$ from the induction surface. Subjects were randomly divided into two groups of 15 anoles each. The control animals were immobilized with their heads held directly under the wooden dowels, with the heads pointed away from the experimenter and the anole turned slightly to one side, so that at least one of its eyes was exposed to the bare dowels. To minimize the lizard's view of the experimenter, he was seated directly behind the subject at a distance $90 \mathrm{~cm}$ away. The experimental group was given the same treatment, but with the glass eyes attached to the dowels. All other procedures were the same as in the first experiment.

\section{Results}

Exposure to the simulated eyes prolonged the duration of immobility almost twice as long as exposure to bare dowels (see Table 1). A transformation $(\sqrt{\mathrm{X}})$ was performed on the data and an ANOVA revealed a significant difference between the two groups $[F(1,28)=$ $5.21, \mathrm{p}<.05]$. The number of inductions needed to elicit immobility was not significantly different.

\section{EXPERIMENT 3}

Since artificial glass eyes were found to prolong the duration of $\mathrm{TI}$ in anoles, the third experiment was designed to assess the effect of pupil to eye ratio on this phenomenon. Previous work by Gagliardi, Gallup, and Boren (1976) found that a 11/20-mm pupil to eye ratio was optimal for chickens, and this study attempted to determine the optimal ratio in anoles.

\section{Method}

Thirty anoles, similar to those already used, were captured and maintained as in the previous experiments. All the materials were the same as in the second experiment, except that the glass eyes were replaced by five pairs of two-dimensional simulated eyes made of black and yellow construction paper. Each eye had a diameter of $2 \mathrm{~cm}$ and a pupil radius of approximately $1,3,5,7$, or $9 \mathrm{~mm}$ (see Figure 1). Six subjects were randomly assigned to each of the pupileye conditions and subjects were immobilized under the eyes in the manner previously described. The durations of TI and the number of inductions were recorded for each subject. Subsequent to this testing, two additional groups of six anoles each were tested under similar conditions while exposed to either totally black or totally yellow spots ( $2-\mathrm{cm}$ radius) suspended from the wooden dowels.

\section{Results}

The means and standard deviations for the durations of TI and the number of inductions appear in Table 1. Although the scores for the two groups tested with the totally black or yellow spots are included in the table to permit comparisons, these data were not included in the statistical analyses since they were collected at a later time. A transformation $(\sqrt{X})$ was performed on the data for the original five simulated eyes and an ANOVA of these transformed scores indicated significant differences between groups $[F(4,25)=3.13, p<.05]$. Subsequent Newman-Keuls comparisons showed that the two lowest durations of TI differed significantly $(p<.05)$ from the highest duration, while other differences did not reach significance. The number of inductions did not differ significantly between groups.

\section{EXPERIMENT 4}

Previous work by O'Brien and Dunlap (1975) found no apparent effect of the overall eye size on durations 


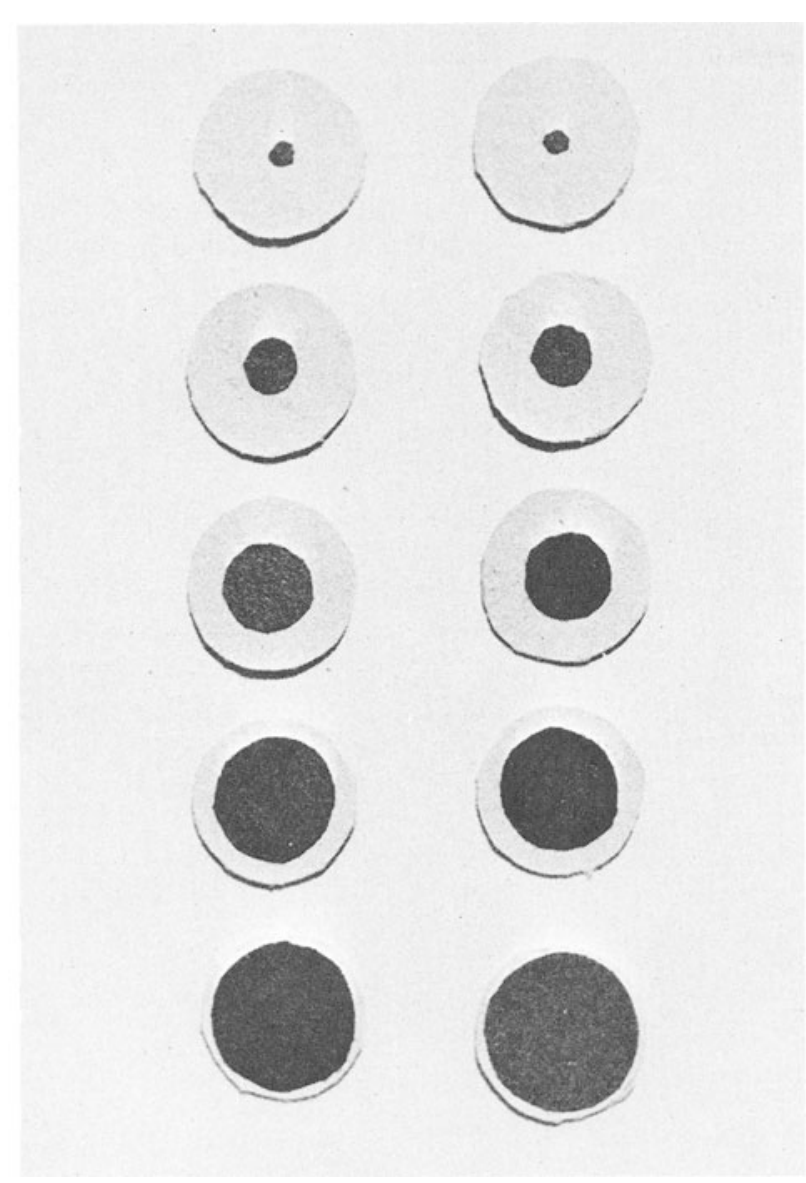

Figure 1. Photograph of the five pairs of simulated construction-paper eyes used in the third experiment.

of $\mathrm{TI}$ in blue crabs. The present experiment was designed to determine if the same was true with anoles when the optimal pupil to eye ratio was employed.

\section{Method}

Forty-four anoles, collected and maintained as in the other experiments, were used as subjects. The pair of simulated eyes with the largest pupil to eye ratio from the previous experiment was used once more. In addition, two larger versions of this pair of eyes, 3.0 and $4.0 \mathrm{~cm}$ in diam with a pupil that was $9 / 10$ the diameter of the eye, were constructed and used in testing. Subjects were randomly divided into four equal groups. One group was tested for TI with the bare dowels and each other group with a different pair of simulated eyes. The method of testing was the same as in the previous experiments.

\section{Results}

The mean durations of immobility for the three experimental groups were considerably longer than that of the control (see Table 1). After transformation $(\sqrt{\mathrm{X}})$ of the raw data, an ANOVA showed a significant difference between groups $[F(3,40)=2.97, p<.05]$. The durations of TI were subjected to subsequent orthogonal comparisons which revealed that only the control group differed significantly from the other three $[F(1,40)=7.67, p<.01]$. The number of inductions required to produce $\mathrm{TI}$ did not differ between groups.

\section{DISCUSSION}

The first two experiments show that eye contact maintained by the experimenter prolonged the duration of $\mathrm{TI}$ in anoles and that detached glass eyes produced a similar, but apparently smaller, effect. This replicates similar findings in the chicken (Gallup, Cummings, \& Nash, 1972; Gallup, Nash, \& Ellison, 1971) and lends support to an across-species generality of these manipulations.

Scaife $(1976 \mathrm{a}, \mathrm{b})$ has shown that variables such as context, orientation, pairedness, and shape affect the distance that chickens will maintain in regard to eye-like stimuli. The second two experiments in this study examined two additional parameters (eye size and pupil to eye ratio) of simulated eyes that might be important in the perception of eye-like stimuli and the prolongation of immobility responses. Although the presence of eyes is not a sufficient condition for inducing TI, eyes may increase fear and therefore potentiate the duration of $\mathrm{TI}$, once elicited. While Gagliardi, Gallup, and Boren (1976) found the optimal pupil to eye ratio was approximately $1: 2$ with chickens, in anoles a dark well-defined pupil seems to prolong TI best: The largest pupils produced the greatest effect, although an entirely black spot had no more apparent effect than did a yellow spot or small pupil to eye ratio models. In addition, while pupil size was of great importance, the overall size of the eye was not. Differences in the duration of TI accompanying various pupil to eye ratios and the apparent lack of effect by eye sizes might reflect differences in the type of eyes found in the major anole predators or might, alternately, be due to certain features of the anole's visual system.

Blest (1957) has shown that eyespots on Lepidoptera are capable of deterring the attack of certain avian predators, and Wickler (1968) noted that so-called eyespots appear in a wide variety of insects and fish, where they seem to possess the ability to fix the attention of both humans and animals alike, as either warning or distraction signals. The experiments of the present study lend support to the general hypothesis that eyes and eye-like stimuli participate in an important way in predatorprey relationships. Overall, the findings of this study, taken in conjunction with past evidence of potentiation of TI by simulated predation, lend additional support to the belief that TI is ecologically related to predation.

\section{REFERENCES}

Blest, A. D. The function of eyespot patterns in the Lepidoptera. Behavior, 1957, 11, 209-256.

Edson, P. H., \& Gallup, G. G., JR. Tonic immobility as a fear response in lizards (Anolis carolinensis). Psychonomic Science, 1972, 26, 27-28.

Gagliardi, G. J., Gallup, G. G., JR., \& Boren, J. L. Effect of different pupil to eye size ratios on tonic immobility in chickens. Bulletin of the Psychonomic Society, 1976, 8, 58-60.

Gallup, G. G., JR. Mirror-image stimulation and tonic immobility in chickens. Psychonomic Science, 1972, 28. 257-259.

GalluP, G. G.. JR. Simulated predation and tonic immobility in Anolis carolinensis. Copeia, 1973, 3, 623-624.

Gallup, G. G., JR. Animal hypnosis: Factual status of a fictional concept. Psychological Bulletin, 1974, 81. 836-853.

Gallup, G. G., JR., Cummings, W. H., \& Nash, R. F. The experimenter as an independent variable in studies of 
animal hypnosis in chickens (Gallus gallus). Animal Behavior, 1972, 20, 166-169.

Gallup, G. G., JR., Nash, R. F., Donegan, N. H., \& MCCLURE, M. K. The immobility responses: A predatorinduced reaction in chickens. Psychological Record, 1971, 21, 513-519.

Gallup, G. G., JR., Nash, R. F., \& Ellison, A. L., JR. Tonic immobility as a reaction to predation: Artificial eyes as a fear stimulus for chickens. Psychonomic Science, 1971, 23, 79-80.

O'Brien, T. J., \& DunlaP, W. P. Tonic immobility in the blue crab (Callinectes sapidus, Rathbun): Its relation to threat of predation. Journal of Comparative and Physiological Psychology, 1975, 89, 86-94.
Sarge ant, A. B., \& Eberhardt, L. E. Death feigning by ducks in response to predation by red foxes (Vulpes fulva). American Midland Naturalist, 1975, 94, 108-119.

ScaIfe, M. The response to eye-like shapes by birds: I. The effect of context: A predator and a strange bird. Animal Behavior, 1976, 24, 195-199. (a)

ScaIfe, M. The response to eye-like shapes by birds: II. The importance of staring, pairedness and shape. Animal Behavior, 1976, 24, 200-206. (b)

WICKLER, W. Mimicry in plants and animals. (R. D. Martin, trans.). New York: McGraw-Hill, 1968.

(Received for publication October 18, 1976.) 